\title{
Intra-action and Interactive Representation of Ethnic Tour Photography Symbols
}

\author{
Zeng Yan \\ (Yunnan Open University, Kunming, Yunnan 650223)
}

Keywords: Photographic symbol; Intra-Action and interaction; Representation

\begin{abstract}
Paying attention to the national tour photography from the perspective of semiotics embodies the vital cultural significance of photography in ethnic tour activities. Through the discussion of the symbolic significance of travel photography and the process deconstruction of the symbolic meaning from intra-action and interactive this paper interprets the connotation of national travel photography. A rich symbolic world is presented in the analysis and elaboration of the intra-action of the tourists as well as the interaction between travelers and various elements in national context.
\end{abstract}

\section{Introduction}

Photography gradually becomes an indispensable content and behavior in people's life along with social development, especially in an alternative lifestyle that pursues spiritual demand - travel, its status and role are more prominent. "Driven by the majestic background of the palace gardens, the Japanese's obsession with snapshots has grown to unprecedented craze. Judging from the continuous snapping sounds of the shutter, not only everyone present, but also every blade of grass, must be fully recorded on film. With a piece of news from "New York Times" of May 3 in 1977, it can be seen that photography and tour, one of the most typical modern activities, develop side by side, a camera fails to be taken in the travel that is taken as such journey for fun and enjoying oneself, which seems to be a thing that is extremely not natural. In modern tour activities, tourists use photography to record and remember their experiences. Tourists record events and things that are considered to be meaningful as well as interesting with cameras. Photos could provide the incontrovertible evidence that proves people have travelled, the related plan has implemented, and moreover, they also have had fun. The photos record the order of consumption outside the view of family, friends and neighbors. [1] In the process of shooting, the tourists are through the lens to know and understand the image in view, accordingly the multi-dimensional communication with the culture and society of the tour destination is produced, then photography in travel has its cultural significance, while this kind of cultural significance has more meaning structure and characterization beyond photography itself. By placing photography to the scene of the ethnic tour, accordingly the ethnic tour with symbolic significance is by way of intra-action and interaction to represent its significance, which adds more forms of expression to the symbolic world of ethnic tour. The intra-action process concerning it means that the tourists improve themselves by internalizing the symbolic meaning in the process of shooting, which makes the tourists get spiritual enjoyment beyond the material, emphasizing the self-experience in the process of national tour. In the process of interaction, the tourists could produce the interaction with the audience, that is other individuals, through the photography process, and they can response to their evaluation, meanwhile, this kind of response could further promote the improvement of tourists' self-worth, this process places emphasis on the interactive experience between the various subjects involved in the national tour as well as the field domain formed by the said subjects.

\section{As the Intra-action Characterization of Tour Attraction}

The photography in the national tour activities is expressed through images, and there is no doubt about the image's symbolic meaning of the picture. In the national tour activities, when you press the shutter on the tour attraction you are interested in, the related scene is recorded. A relationship 
has been produced between the image in the photo and the tour attraction, and such relationship is called the "symbol-code relationship". (Peng Zhaorong, 2004) That is to say the image in the photo is the decoding as well as reproduction of the actual scene. In addition, this image symbol indicates that such image exists in a national tour scene. Especially when these image symbols are taken as the promotion for the tour traders, agencies, media, tourists have received a series of tour information of picture ads, postcards, brochures and so on before entering into the actual national tour activities, under the circumstances, the corresponding "attraction" effect is produced, so the tourists will head for "there" in accordance with the instruction of the pictures. National tourists enter into the process of the national tour from daily life, which is just the role transformation from the self in real life to the new self in the travel scene, I of the everyday life becomes a tourist, while this tourist is the expectation of the residents of the tour destination for me being a "tourist", I temporarily abandon conventional life in my experience of the ethnic culture, like a "native". Tourist's photographic process is a process of recording my journey to "there", a process of role transformation and a process of positioning self-role.

\section{As the Interactive Representation of Tour Souvenirs}

The anthropologist Victor Turner thinks that symbolic signs can be objects, behaviors, relationships, events, postures and space units in their context. (Victor Turner, 1970) Symbolic signs understood in this sense are not only the representation between objects and objects, but also the representation between any elements mentioned above. Photography's main function is to keep the ethnic tour scene at that time, tourists could obtain people's memory of the scenery or spots in the travel situation through repeatedly viewing the photos taken on the spot, the photos will be retained for a long time, staying in tourists' "photograph album" and "photo album" as a souvenir. Photos confirms the tourist himself/herself in travel situation at that time, which is taken as the material evidence of "visiting this place", [2] as the personal creation of a "material symbolic sign", which is the characterization of the personal state in the tour scene at that time, when leafing through the said photos every time, the relevant things at that time occur to the mind of the tourist. Photography in the travel is considered the "counterpart" of all kinds of things and relationship occurred in the tour activities, accordingly photography as a tour souvenir has become a kind of special symbol expression with the natural "material culture", namely material symbolic sign "kinen", which has become the core part in the tour souvenir's symbol system. The photos can be taken as a kind of "omiyage" when viewed from another perspective, which can be displayed and given to others as an important gift, let others share personal experiences with you. [3]

Therefore, photos have become one of the important ways to arouse the tour expectation and express the tour experience. The basic motivation of tourists to shoot is to prove, commemorate and remember the related things. Tourists hold up their cameras frequently to shoot in the process of appreciating national culture, leaving countless beautiful moments in their cameras (Liu Danping, Bao Jigang, 2006). The process of taking photos is not only the process of interaction between tourists and local residents, but also the process of interaction with local national culture and scenes. Photos are not only the basis of their memories, but also the evidence of displaying their travel experiences to others. When tourists bring back the photographic works as the tour experience to elaborate the relevant culture there to the local community, meanwhile, the related information is showed to the community residents by way of displaying the corresponding photography, accordingly the culture of the national tour destination begins to exchange with the social culture involving the tourists at that time.

\section{As the Interactive Representation of Tour Experience Narrative}

The basic function of photography is to use images presented in photos for expression, therefore, photos become the expression of the "texts" for tourists by way of their personal perspectives and choices. Peng Zhaorong thinks that the way of expression of travel photography is just "discourse narrative", as a result, the tourists have built their specific "context" by using photography for 
conducting the narrative concerning the "text", while photographs become the "text" symbols of "discourse narrative" in the tour situation. All the following factors of tourists are in different positions, stand in disparate angles, make use of different light, they are in different cultural backgrounds, have different mental states, apply different photographic media (film, digital photography), adopt different photographic skills and so on have determined that they can form the unique image in the same "real scene", which is called "image invention" by Peng Zhaorong, because the image symbol is "made" by people. The process of "making" is the process of decoding "real scene" into "symbolic code", the various "languages" of color, artistic conception and emotion concerning it are formed in the process of "symbolic code" conducting narrative for the "text", meanwhile, the different "contexts" in the ethnic tour situation are also constructed. In the "context" of national tour situation, it is the communication between the "viewer" and the target to be photographed, and it contains the tourists' understanding of the national culture, understanding and perception of the cultural background of the national tour destination, which is the special "context" constructed by the cultural value and social culture. National tour photography connects all the things and elements in tour activities, including the entire people, scenery and things involved in national tour scenes. The various cultures in the process of the ethnic tour activities are recorded in the pictures, in addition, the national tour destination and residents, or other events, behaviors occurred, the state of the local residents and the connection with the national tour destination are also recorded, the photograph of infinitesimal unit one by one constitutes the social reality. What the photos represent is about the relation of all kinds of things and factors of national tour destination, which is the symbol of the relationship between a cultural value and society, this relationship lies in the multi-dimensional communication between the tourists and the national tour destination. [3] As the "text symbol", photo narrates the social reality in the national tour situation, at the same time; it also elaborates the accumulation process and experiencing process of national tour experience. National tour photography has become a kind of link between "native" and "non-native" ethnic groups, the bridge between the public and the world.

\section{As the Intra-action Characterization of Tour Ceremony}

In the study of tour anthropology, there is a common view that modern tour is a kind of modern ceremony, while travel photography records the ceremonies, accordingly the whole process of the ceremony is showed in the photo. Under the circumstances, tour photography has become a kind of ceremony to record the travel life experience, which belongs to the travel ceremony. Travel photography occurs in the process of tour, tourists of this phase are in a kind of "the center of excitement", which possesses the "holy" meaning on its symbolic significance, tourists enjoy the "holy time" at this stage. Tour photography solidifies the "sacred feeling" of this stage through photos, and condenses "other time, other people, other scenery" into the specific time and space. However, after the ethnic tour activity comes to an end, when the tourists take photos back to the stage of real life with "bitter and sweet mixed", although the tourists have returned to the secular life, but "the present I" is different from the "I of the past", with continuous review of photos, people at the present stage can take themselves back to the "past" travel scenes at any time through memories, solidified in the space and time of the past. Photographs can be better memorized than dynamic images, because they are a kind of time that is neatly cut, which will strengthen the role of time and space, make the "holy process" of the tour scene at that time across the time tunnel and form the corresponding relation with the present "secular life". In this process, tourists find that the "secular life" in the past is different from the "secular life" at present for having added the experience of national cultural scenes. Solidified time and space relationship brings tourists into the tunnel of time and space, moving in the modern age, the past and the future, while the time and space solidified in photographic pictures will also take the tourists into yearning for the space and time in the future, instructing the tourists heading for the "holy life" of the tour scene again in the future, which will take the tourists into the time and space scene of the travel in the future. Therefore, tourists have carried out a multicultural baptism of time and space through photography.

Now national photography has gained the construction as well as characterization in the 
symbolic world of the ethnic tour scene, as tour attraction, travel souvenir, tour experience and travel ceremony and other symbolic significance, national tour photography is conducting the characterization of intra-action and interaction in the course of cultural development, at the same time, it makes the constant enrichment as well as development in the world of travel.

\section{Acknowledgement}

Scientific research fund of the Yunnan Provincial Education Department: Research on the economic operation path of traditional culture symbols in Ethnic Tourist Destinations

\section{Reference}

[1] Susan Sontag. Translated by Huang Canran. On photography [M]. Shanghai: Shanghai Translation Publishing House, 2008:225.

[2] Peng Zhaorong. Anthropology of Tour [M]. Beijing: Ethnic Press, 2004:175.

[3] Nelson Grambum. Translated by Zhao Hongmei et al. Anthropology and the Age of Tourism [M]. Guangxi: Guangxi Normal University Press, 2009:295-298.

[4] John Urry. Translated by Yang Hui, Zhao Yuzhong, Wang Qingling, Liu Yongqing. The Tourist Gaze [M]. Guangxi: Guangxi Normal University Press, 2009:173-178.

[5] Victor Turner. Translated by Zhao Yuyan, Ou Yangmin, Xu Hongfeng. Symbolic Forest [M]. Beijing: Commercial Press, 2006:25.

[6] Zhang Xiaoping. Anthropological Perspectives on Ethnic Tour [M]. Yunnan: Yunnan University Press, 2009:211.

[7] David Popono. Sociology [M]. Renmin University of China Press, 2002: p148-190.

[8] Xie Yanjun et al. Research on Tour Experience - towards Empirical Science [M]. Beijing: China Tour Publishing House, 2010:27,37-38.

[9] Zhang Xiaoping, Li Wei. Tour Anthropology [M]. Tianjin: Nankai University Press, 2010. [10]Wang Ning. Tourism and Modernity: A Sociological Analysis [M]. Pergamon Press: 2000. 